University of Pennsylvania Carey Law School

Penn Law: Legal Scholarship Repository

Faculty Scholarship at Penn Law

1996

\title{
Technology Assessment and the Doctor-Patient Relationship
}

Amy L. Wax

University of Pennsylvania Carey Law School

Follow this and additional works at: https://scholarship.law.upenn.edu/faculty_scholarship

Part of the Bioethics and Medical Ethics Commons, Health and Medical Administration Commons, Health Services Administration Commons, and the Law Commons

\section{Repository Citation}

Wax, Amy L., "Technology Assessment and the Doctor-Patient Relationship" (1996). Faculty Scholarship at Penn Law. 1278.

https://scholarship.law.upenn.edu/faculty_scholarship/1278

This Response or Comment is brought to you for free and open access by Penn Law: Legal Scholarship Repository. It has been accepted for inclusion in Faculty Scholarship at Penn Law by an authorized administrator of Penn Law: Legal Scholarship Repository. For more information, please contact PennlawIR@law.upenn.edu. 


\title{
TECHNOLOGY ASSESSMENT AND THE DOCTOR-PATIENT RELATIONSHIP
}

\author{
Amy L. Wax
}

Professor Elhauge's main thesis is that technology assessment is unlikely to slow the cost explosion in health care. 'Ideally, technology assessment would identify unnecessary, ineffective, or excessively expensive methods for treating or evaluating illness, or for delivering health care. But, according to Professor Elhauge, technology assessment does not prove useful in altering the patterns of consumption of medical care or in reducing inefficiencies. Significant savings cannot be achieved over the long run by wringing "waste" from the system, and neither elimination of medically useless therapies nor the development of more efficient methods of treatment or delivery of care will reduce the inexorable cost escalation that has been a feature of our medical care system for decades. Rather, significant control of health care costs will require moving beyond a quest for mere efficiency - the achievement of the most benefit for the least cost-to medical rationing, which entails trading off real health care benefits. ${ }^{2}$

According to Professor Elhauge, the route to cost savings through

- Professor of Law, University of Virginia School of Law. I am grateful for the able research assistance of Eliza Platts-Mills.

' Einer Elhauge. The Limited Potential of Technology Assessment, 82 Va. L. Rev. 1525 (1996). Professor Elhauge distinguishes purely "informational" technology assessment from "regulatory" technology assessment. He describes "regulatory" technology assessment as the process of using information to allocate health care resources. "Informational" technology assessment is the process of gathering systematic data about the benefits and costs of medical therapies, techniques, and treatment strategies. See id, at 1527-29. Medical technology assessment, or a component of what Professor Elhauge refers to as "informational" technology assessment, typically takes the form of "outcomes research," which involves "examining large amounts of data about rates of various outcomes given various treatments" in well-defined populations of patients. Fred Gifford, Outcomes Research and Practice Guidelines: Upstream Issues for Downstream Users. Hastings Ctr. Rpt., Mar-Apr. 1996, at 38, 38. It requires "statistical analyses of outcome data drawn from very large data bases." Id. These include data sets generated specifically for the purpose of evaluating the therapies at issue, as well as pre-existing data compilations in the form of company records, insurance files, or hospital charts. Id at 38 39; see also Sandra J. Tanenbaum, Knowing and Acting in Medical Practice: The Epistemological Politics of Outcomes Research, 19 J. Health Pol. Pol'y \& L. 27 (1994).

"Elhauge, supra note 1, at 1546-47. I use the term "medical rationing" in reference to Professor Elhauge's notion that if there is to be a reduction in the ever-increasing portion of national wealth devoted to medical care, some patients within the system must sacrifice some degree of the well-being that could be achieved by providing all potentially available care. 
medical rationing is effectively blocked by the absolutist paradigm, which mandates that no patient be denied any treatment known to be medically beneficial, however marginal the benefit or however great the cost. This absolutist imperative has a firm grip on the medical establishment, Professor Elhauge contends, and is relentlessly enforced by a variety of powerful forces and institutional agents, operating on multiple levels within the existing health care system. ${ }^{3}$ Against this dominant paradigm, Professor Elhauge argues, technology assessment is virtually useless. The problem of exploding health care costs stems not from lack of information-which is what technology assessment is designed to provide-but from other factors, such as the inability to agree on the morality and desirability of rationing, the lack of a coherent and unproblematic protocol for allocating limited medical resources, and the absence of a workable institutional framework for enforcing a comprehensive rationing scheme. ${ }^{4}$

In challenging Professor Elhauge's view of the potential for technology assessment to achieve cost control, I begin with our points of agreement. I accept, for purposes of this Comment, that if rationing means that someone, somewhere, will forgo at least some possibility of medical benefit," then some kind of rationing-as opposed to mere "waste" reduction-is probably necessary to arrest the relentless inflation of health care costs. There is also no denying that the absolutist mindset-which opposes planned limits on individuals' access ${ }^{6}$ to treatment that is be-

\footnotetext{
${ }^{3}$ See Elhauge, supra note 1, at 1537-38.

+ Id. at 1526-31.
}

"Of course, defining rationing as the relinquishment of some "known" medical benefit is not very informative, because the medical effects of even commonly used therapies can be estimated only by observing probabilities in populations that can potentially be categorized, subdivided, and tested in many different ways. The categories of "known" benefit, "possible" benefit, and "unknown" benefit are best thought of as points on a constantly fluctuating continuum that is a function both of the observed effects of a treatment in particular populations and of how much information has been gathered in populations of different size and characteristics. The size of the population studied is particularly critical to the ability to measure effects of therapies: for example, benefits that do not show up in a smaller population may be revealed in a larger one. As a rough rule of thumb-and one that inevitably piggybacks on the somewhat arbitrary conventions of epidemiology-I would define the possibiiity of benefit as coextensive with a statistically significant chance of observing a measurable effect (however small) in some patients within a population of the size usually considered adequate to evaluate the efficacy of a particular therapy. Taken to its extreme, the absolutist paradigm would require that a treatment be made available even if there was a very small chance of conferring a minimal, but statistically detectable, benefit on a few persons in a large target population with a particular condition. Such a benefit could be described in many different ways. There is a "real" or "known" benefit in the sense that someone in the target population can be expected to experience some positive effect, however minimal. But, the benefit is "uncertain," or even "unlikely," to the extent that only a very small number of patients will respond, the response is small, and the patients cannot be identified ahead of time.

"Professor Elhauge notes that our society seems more tolerant of institutional priorities 
lieved to present some chance of medical benefit, however remote? holds considerable sway in the health care community.

Beyond those major areas of agreement, 1 must part company with Professor Elhauge. Here I speak primarily as a physician and former practitioner-as someone who has done time "down on the ground"rather than as a legal scholar or a theorist of health care delivery systems. I disagree with Professor Elhauge's central conclusion that technology assessment is useless against the influence of the absolutist paradigm that pervades the health care establishment. On the contrary, technology assessment has a vital role to play in helping to subvert the hostility towards cost-benefit tradeoffs.

The choice of the word "subvert" is quite deliberate. As Professor Elhauge has explored elsewhere, the task of formulating, justifying and setting up a comprehensive system of rationing presents overwhelming challenges of justification and coordination. It is virtually impossible to devise a fully satisfying and theoretically coherent rationing system that is completely consistent with all our principles and moral commitments. Therefore, the idea of rationing has come to acquire a bad name among philosophers, analysts and health care experts, and is unpopular with health care decision makers who are charged with publicly justifying their allocational decisions (such as university medical centers, governmental policymakers and judges).

I submit, however, that these theoretical tensions have simply pushed rationing underground: It is practiced covertly or informally, defying the uncompromising claims of absolutism in small and subtle ways. Rationing governs practice far more than express theoretical commitments, and hence is the purview of those who function on the "front lines" of the system. The day-to-day business of placing limits on care is an ad hoc, decentralized, piecemeal, informal, intermittent, intensely local and often erratic phenomenon - which makes it hard to discuss, difficult to demonstrate, and almost impossible to survey and quantify. Providing definitive evidence of the existence and extent of actual rationing, therefore, is not easy. It is the task of an empiricist, not a theoretician. It is the job of a medical sociologist or anthropologist, not a philosopher or professor of

that risk future detrimental effects on persons who cannot be identified ahead of timeso-called statistical lives-than it is of allocative methods that deny care to specified individuals who are known to be in immediate need of medical intervention. See Elhauge, iupra note 1 , at 1570 .

Because the concept of medical benefit is inextricably bound up with considerations of uncertainty and risk, the meaning of the phrase "some chance of medical benefit," is open o debate-a debate that is reflected in the literature regarding the definition of medical utility. See supra note 5 , and infra note 38 and accompanying text.

"Einer Elhauge, Allocating Health Care Morally, 82 Cal. L. Rev. 1449 (1994) hereinafter Elhauge, Allocating Health Care Morally]. 
law. The premise of this Comment-which must provisionally be taken on faith-is that rationing goes on every day in the practice of medicine, in a form that presents real tradeoffs between costs and benefits. Armchair analysis can only take us so far in satisfying those who may be skeptical of this premise.

Thus, the rationing I describe and discuss in this Comment differs from the rationing with which Professor Elhauge has been primarily concerned in his role as a legal scholar and student of the health care system. In his previous work, Professor Elhauge has been preoccupied with centralized, bureaucratic, "top-down" mechanisms of rationing." This is understandable, since he has set out to devise and justify a comprehensive system for allocating health care resources. In accomplishing this project, he necessarily seeks theoretical consistency, which requires examining transystemically all decisions made for all patients within a complete and closed system of care.

While any fully rigorous and theoretically satisfying rationing system must be global, most real-world rationing remains firmly local. In a recent piece, ${ }^{10}$ Professor Mark Hall describes the complexity and character of real-world rationing, and offers a defense of physicians' practice of limiting, forgoing, or delaying potentially beneficial care of individual patients on a case-by-case basis - a practice he terms "bedside rationing." How does rationing at the bedside work? The key is that it is uncoordinated, sporadic and informal. It is accomplished through the type of messy, ad hoc decision-making that physicians and patients engage in every day.

The ideal of quality care has come to be equated with care that is tailored to the individual patient, but in a way that is fully cognizant of sound scientific principles. Indeed, it is unlikely that medical care that departs from this model can be, or has ever been, considered good. Decisions concerning the provision, intensity and duration of care are routinely made on a highly individualized basis, in conjunction with, and after consultation with, patients and their families. The model of individualized care, although not without potentially serious drawbacks and temptations (such as its ever-present invitation to an unrigorous anecdotal approach), also opens the door to rationing of a very modest and discreet kind. That rationing takes the form of "the prudent trimming of

Id. at 1493-1502, 1508-26.

"Mark A. Hall, Rationing Health Care at the Bedside, 69 N.Y.U. L. Rev. 693 (1994).

${ }^{11}$ Id. at 699. For another defense of physician-implemented limits on care, see David Orentlicher, Paying Physicians More to Do Less: Financial Incentives to Limit Care, $30 \mathrm{U}$. Rich. L. Rev. 155 (1996). 
incrementally beneficial services," choices between the use or outright denial of clearly lifesaving treatment. Bedside rationing is best characterized as a method of responding to the day-to-day need to make small decisions in an atmosphere of partial uncertainty and speculative possibilities, rather than as an intentional relinquishment of the precisely defined benefits of well-understood methods.

Bedside rationing is a creature of the conservatism that is one very important element of the cluster of values and norms that inform the practice of medicine. It is a by-product of a cautious, less intensely interventionist practice style that still retains a significant degree of influence within the profession. It balances tradition, local convention, and trust in clinical judgment against the all-out reliance on expensive new technologies. In mapping out strategies that present some risk of forgoing medical benefit, as Professor Hall puts it, "[c]ost-benefit trade-offs [are] largely subliminal in physicians' thought processes, "13 rather than overtly considered. Cost considerations are unconsciously internalized as one of many factors bearing on the choice of particular treatment strategies. A pronounced disproportion between cost and benefit might subtly sway the decision-making process. Certainly, cost considerations help shape many physicians' sense of the appropriate pace and aggressiveness of approach to particular medical or diagnostic problems.

In sum, financial considerations probably influence medical decisionmaking "on the ground," but their influence is imperfect, fluctuating, and indirect. Cost pressures and concerns find expression through evolving traditions and conventions of accepted practice, rather than through the rigid imposition of explicit rules which would mark the type of centralized rationing regime with which Professor Elhauge is most directly concerned.

That cost considerations do come into play should come as no surprise, The habits of practicing physicians have evolved in practice settings in which resources have often been limited. The widespread availability of health insurance is a phenomenon barely fifty years old in this country. ${ }^{14}$ There are approximately forty-two million uninsured persons in the United States, according to a recent report. ${ }^{15}$ Physicians must routinely cope with the limitations imposed by the difficulty of paying for care. The internalized habits of restraint, which remain useful in dealing with

12 Hall, supra note 10 , at 712 .

"Id. at 713 .

is See Herman M. Somers \& Anne R. Somers, Doctors, Patients, and Health Insurance 10-11 (1961).

1* See E Richard Brown, Data Watch. Trends in Health Insurance Coverage In California, 1989-1993, Health Aff., Spring 1996, at 118, 120. 
uninsured patients, carry forward traditions from an era when few had medical insurance and cost was a factor in most patients' care. ${ }^{16}$ Even today, educational practice, local custom, and peer pressure continue to foster those traditions to some extent, shaping those notions of wise or prudent medical care. Recent cost-cutting imperatives, fueled by institutional changes that favor fixed-fee over fee-for-service forms of reimbursement, are likely to reinforce, rather than extinguish, the conservative habits that retain influence in some quarters, even in the face of the relentless escalation in the expectations for care that have been fueled by countervailing forces. ${ }^{17}$ To be sure, conventions of practice are in con-

${ }^{16}$ To be sure, the costs of routine medical care were far less onerous for the average person before the insurance era. There also were far fewer treatment options. But it is important to remember that basic tenets of medical ethics and practice were established at a time when the majority of patients paid for medical care out of their own pockets,

${ }^{17}$ Traditional fee-for-service medicine provides few incentives for physicians to limit care, and rewards physicians for providing physician-based services. Since physicians receive reimbursement for each service provided, they enhance personal income only by providing more services. See Orentlicher, supra note 11, at 158. Moreover, fee-forservice patients "are not very discriminating purchasers of health care," nor do they have much incentive to limit their consumption of medical services. Id. at 188-89. It is widely accepted that the combination of fee-for-service medicine and coverage based on "medical necessity" is a sure formula for cost explosion. The inflationary pressure is greatest for patients covered by health insurance plans that are highly deferential to the physician's judgment of what is "medically necessary" care. Such plans dominated the scene during the first few decades of the post-war period, and influenced the initial design of Medicare. See Judith M. Feder, Medicare; The Politics of Federal Hospital Insurance 53-57 (1977).

Fee-for-service medicine has gradually given way to fixed-fee arrangements for delivering health care (although fee-for-service remains an important fixture of the medical scene, albeit in more cost-conscious forms). Private health maintenance organizations ("HMOs") typically pay physicians by a capitation method (a set amount for every patient seen or cared for) or by a fixed salary. HMO compensation methods were designed to mute the incentive to provide additional, possibly unwarranted, care that existed under a fee-for-service regime. HMO compensation methods accomplish this goal only imperfectly and at the cost of creating a different set of potentially perverse incentives. For example, payment by way of fixed salary may lead a physician to see fewer patients or to spend less time with them, since the physician receives the same payment regardless of how hard he works. Capitation places a premium on seeing as many patients as possible, decreasing the time spent with each. Further, "[e]ven with their built-in incentive to limit care, pure salary and capitation may not provide sufficient incentive for physicians to limit the costs of care provided to their patients." Orentlicher, supra note 11 , at 159. Under both arrangements, physicians may seek to satisfy their patients by "alter[ing] the mix of services provided," id, in a way that relies less on the primary physician's attention, and more on ancillary services such as sophisticated tests, complicated and protracted therapies, or specialty care. See id, at 159-60. The end result could well be an increase rather than a decrease in overall costs.

To counteract these tendencies and minimize physicians' use of ancillary services, health care plans have relied on other devices such as bonuses, fee withholds, or expanded capitation. See id. at 160 (outlining the mechanics of these devices). The common feature in these payment methods is that the physician stands to earn more by limiting patients' use of ancillary services, including outside referrals, expensive treatments, 
stant flux, and it is difficult to assess the relative salience of different strands of professional tradition in setting the standards of care. It is reasonable to expect that even physicians who are most insulated from cost constraints (like fee-for-service physicians treating fully-insured patients) are not wholly immune to the influence of physicians who operate under greater cost constraints. The point is that medical practice is not a monolith. Moreover, the changes and upheavals now underway in the organization of health care may foment additional, as yet unknown, shifts in the grass-roots balance of culture and influence that determine the standards and methods of medical practice.

It is not possible to address here the difficult question of whether bedside rationing in any of its various forms can be defended. ${ }^{18}$ Rather, the point of this Comment is that any credible commentary on the role of technology assessment must accept that the actual hold of the absolutist

hospitalizations, and diagnostic tests.

${ }^{18}$ Bedside rationing is highly controversial. It has been condemned as unworkable, unethical, and theoretically indefensible. See Elhauge, Allocating Health Care Morally, supra note 8 , at $1465-72$ (reviewing arguments critical of bedside rationing); Hall, supra note 10 , at 703-11 (same). Critics of physician-based rationing rely on many of the same arguments that are directed at institutional and rule-based schemes, and raise additional objections that are specific to physician-directed limitations on care, including the potential conflict of interest created by the physicians' paramount obligation to vindicate the interests of the patient and to use best medical judgment, and the inability of individual physicians to take cognizance of systemic concerns of fairness and comparative need. See, e.g., Hall, supra note 10, at 703-05 \& nn.31-32 (reviewing opposition to bedside rationing based on concern about the physician's role in the rationing decision); Orentlicher, supra note 11 , at 165 (acknowledging that under a physician-based rationing regime, "there would be a great deal of inconsistency from physician to physician," and that treatment decisions might "turn more on the personal views of the patient's physician than on any overarching rationing principles").

Attempts by health care provider organizations, such as HMOs, to create financial incentives for physicians to limit care have encountered particularly adamant opposition. See, e.g. David M. Frankford, Managing Medical Clinicians' Work Through the Use of Financial Incentives, 29 Wake Forest L. Rev. 71 (1994) (concluding that the use of financial incentives is likely to result in increased conflict rather than greater control); David Mechanic, Professional Judgment and the Rationing of Medical Care, $140 \mathrm{U}$. Pa. L. Rev. 1713, 1748 (1992) ("Ip]ersonal remuneration arrangements that improperly modify medical decision-making by providing economic incentives to doctors to withhold services should be prohibited"); Orentlicher, supra note 11, at 161-62 (discussing critiques that characterize the use of financial incentives to limit care as a threat to patient welfare and a violation of the fiduciary nature of the physician-patient relationship): Daniel P. Sulmasy, Physicians, Cost Control, and Ethics, 116 Annals Internal Med. 920, 923-24 (1992) (critique of arguments in favor of financial incentive control); see also Steffie Woolhandler \& David U. Himmelstein, Extreme Risk-The New Corporate Proposition for Physicians, 333 New Eng. J. Med. 1706 (1995) (expressing fear of anticipated ill effects from HMO cost-consciousness). But cf. Hall, supra note 10 , at 706 ("A divergent wing of less absolutist physicians and ethicists are more accommodating to bedside rationing.") \& n.37 (collecting sources of support of this position by ethicists); Orentlicher, supra note 11 . at 156-58, 192-97 (arguing in favor of physician-based rationing and financial incentives to limit medical care). 
paradigm, although formidable, is less than absolute, because bedside rationing remains an important force in medicine today. My thesis is that technology assessment has a vital role to play in nourishing and maintaining the practice of bedside rationing, and in insuring that the practice is not abused. Absolutists find all forms of rationing unacceptable, but even those who defend the practice recognize that abuses are possible." I submit that the most important source of arbitrary and indefensible limits on care is ignorance, and it is technology assessment's role to reduce ignorance.

To understand how technology assessment could encourage physicianbased rationing of the most benign form, one must accept three important propositions about the real world of medicine. First, when costbenefit tradeoffs are made in actual medical practice, they are often based not on accurate information but on intuition, prejudice, anecdote, or unsubstantiated lore. Care-limiting decisions that are informed by medical outcomes data generated through technology assessment - which I would term "well-informed rationing"-are comparatively rare. Second, most instances of rationing will be confined to "cutting corners" or forgoing treatment "at the margins." That is, a decision not to do "everything possible" (at least not all at once), will usually be made because the physician and patient believe that the benefits of the interventions at issue will be modest or quite uncertain, or that the possible advantages will be counterbalanced by the threat of significant complications or side effects. Third, as Professor Elhauge himself acknowledges, ${ }^{20}$ much recent new medical technology and innovation-both in diagnosis and treatment-is of small marginal benefit compared with existing methods. Methods that save or dramatically improve the life of all those afflicted with a particular life-threatening disease are now few and far between. ${ }^{21}$ Positive effects will be seen in only a few patients within the target group, and these effects will be of modest magnitude or transient duration. Rarely do new therapies present the beneficial equivalent of penicillin, insulin or appendectomy. That is not to say that there are no significant advances whatsoever. ${ }^{22}$ For whatever reason, however, most progress

10 Defenders include Professors Hall and Orentlicher. See Hall, supra note 10. Orentlicher, supra note 11 .

2. Elhauge, supra note 1, at 1546 (arguing that the health care system has recently made "a lot more care available with a high cost relative to its benefit").

3 The reason for this trend is unclear. It may be that medical science has tackled the "easy" problems, so that only the complex and difficult ones remain. For a discussion of possible faclors behind the slowing of scientific progress, see generally John Horgan. The End of Science: Facing the Limits of Knowledge in the Twilight of the Scientific Age (1996)

"The drug taxol, for example. has made a significant difference in prognosis and quality 
now comes in slow increments, and new agents usually offer very small marginal gains. ${ }^{23}$ And those benefits are often purchased at extravagant cost. Most new drugs are expensive, due in large part to the prolonged and risky process of development, and the elaborate and extensive clinical testing required to satisfy Food and Drug Administration (FDA) standards of safety and efficacy. ${ }^{24}$ The protections afforded by the patent system and other legislation designed to shelter investment and reward innovation $^{25}$ combine with the demands of new drug development to drive up the cost of even the most marginally useful treatments.

There are many examples of new medical technologies for which cost is extremely high, and benefit is slight, marginal or unproven. For example, in treating metastatic breast cancer, the use of bone marrow transplantation is extremely expensive, potentially traumatic and risky. Virtually every well-controlled study has failed to show that the treatment has any statistically significant effect on duration of survival. ${ }^{26}$ Similarly, a

of life for patients with ovarian cancer. See Monroe E. Wall \& Mansukh C. Wani, Camptothecin and Taxol: Discovery to Clinic-Thirteenth Bruce F. Cain Memorial Award Lecture, 55 Cancer Res. 753, 757 (1995) (citing "numerous observations of partial and complete remission of advanced ovarian cancer in women"). Despite the proliferation of new drugs and treatment protocols, the pace of progress for many forms of cancer has been disappointing. See David Plotkin, Good News and Bad News About Breast Cancer, Atlantic Monthly, June 1996, at 53; see also John Rennie \& Ricki Rusting, Making Headway against Cancer, Scientific Am., Sept. 1996, at 56. See generally What You Need to Know About Cancer, Scientific Am. (Special Issue), Sept. 1996.

${ }^{2}$ For examples of the small marginal benefits that new agents offer, see infra notes 2628 and accompanying text.

${ }^{24}$ See, e.g. Kenneth I. Kaitin, Michael Manocchia, Mark Seibring \& Louis Lasagna, The New Drug Approvals of 1990, 1991, and 1992: Trends in Drug Development, 34 J. Clinical Pharmacology 120, 125-27 (1994) (discussing delays in FDA approval of new drugs); see also Kenneth I. Kaitin, Nancy Mattison, Frances K. Northington \& Louis Lasagna, The Drug Lag: An Update of New Drug Introductions in the United States and in the United Kingdom, 1977 through 1987, 46 Clinical Pharmacology \& Therapeutics 121, 1.33 tbl $x$ (1989) (charting the United States' lag behind the United Kingdom in introducing endocrine agents); Patricia J. Kenney, The Orphan Drug Act-Is it a Barrier to Innovation? Does it Create Unintended Windfalls?, 43 Food Drug Cosm. L.J. 667, 667-68 (1988) (citing the assertion made by the Pharmaceutical Manufacturers Association that the average new drug takes ten years and costs over 100 million dollars to bring to market).

${ }^{25}$ See Drug Price Competition and Patent Term Restoration Act of 1984, Pub. L. No. 98-417, 98 Stat. 1584 (1984) (extending patent life on selected brand-name drugs); 21 U.S.C. $\$ 360 \mathrm{bb}(\mathrm{a})(2)$ (1994) (defining rare diseases as diseases affecting less than 200,000 persons in the United States, or diseases affecting more than 200,000 people in the United States, but for which there is no reasonable expectation that the cost of making the drug will be recovered in sales of the drug in the United States); see also Kenney, supra note 25 , at 668 (arguing that to encourage the development of drugs for rare diseases, economic incentives are needed).

${ }^{26}$ See, e.g., Thomas J. Smith, Bruce E. Hillner \& Christopher E. Desch, Efficacy and Cost-Effectiveness of Cancer Treatment: Rational Allocation of Resources Based on Decision Analysis, 85 J. Nat'l Cancer Inst. 1460, 1468 (1993) ("there are no randomized clinical trial data confirming that this therapy is more effective than standard treatment"); 
number of drugs recently approved by the FDA show modest, short-lived or ambiguous effects. Demonstrating that these drugs have any benefit whatsoever requires trials of many thousands of patients. Scientists must conduct sophisticated and sometimes problematic statistical analyses in an often unsuccessful attempt to identify subgroups of patients who might be helped by the drug. With respect to diagnostic techniques the situation is not much different. New scanners, screening techniques, and blood tests significantly add to medical expenditures overall, but frequently present only a marginal improvement over existing methods, provide a net health benefit that is very difficult to measure, or have a high error rate that confounds their usefulness. ${ }^{28}$

see also Mark A. Hall \& Gerard F. Anderson, Health Insurers' Assessment of Medical Necessity, 140 U. Pa. L. Rev. 1637, 1637-38 n.3 (1992) (citing studies).

${ }^{n}$ Recent examples demonstrating this phenomenon include Betaseron for multiple sclerosis, see Anne Allen, The High-Stakes Drug Drawing, 9 J. Post Anesthesia Nursing 52,53 (1994) (describing the time-intensive process required for FDA approval of Betaseron for multiple sclerosis); Interleukin-2 for renal cell cancer, see B. Escudier, Immunothérapie dans le cancer du rein métastatique [Immunotherapy for Metastatic Renal Cell Cancer], 24 La Presse Médicale 1504, 1504 (1995) (emphasizing the need to continue rigorous clinical trials of interleukin-2 as a treatment for metastatic renal cell cancer); granulocyte-macrophage colony-stimulating factors ("GM-CSF") for low blood counts associated with AIDS and cancer, see Regis T. Costello, Therapeutic Use of Granulocyte-Macrophage Colony-Stimulating Factor (GM-CSF): A review of recent experience, 32 Acta Oncologica 403, 406 (1993) (concluding that the full benefits of GMCSF in cancer therapy have still to be proven, and that the drugs' "effective benefit has to be very carefully evaluated before extensive use of such sophisticated and expensive therapy"): Tacrine for alzheimer's disease, see M. Lynn Crismon, Tacrine: First Drug Approved for Alzheimer's Disease, 28 Annals Pharmacotherapy 744 (1994) (arguing that despite FDA approval of Tacrine for treatment of Alzheimer's disease, clinically meaningful effects have not been demonstrated); Gina Kolata, Hopes Are Rosy on Alzheimer's, But Results Slim, N.Y. Times, July 30, 1996, at C1, C3 (describing the "one drug on the market [Tacrine]" for Alzheimer's disease as "marginally effective at best"); Proscar for benign prostatic hypertrophy, see Lawrence K. Altman, U.S. Study Compares Merits of Leading Prostate Drugs, N.Y. Times, Aug. 22, 1996, at A18 (reporting on a clinical study showing that Proscar, which treats the symptoms of benign prostatic hypertrophy, "is no better than a dummy pill or placebo"); and tPA for post-heart attack coronary artery atherosclerotic blockage, see Robert McNutt \& Arthur Evans, Accelerated tPA versus Streptokinase for Suspected Myocardial Infarction: Waiting for our Mountain Dew, 15 Med. Decision Making 395 (1995) (claiming that extensive clinical trials that compare responses to tPA and to the less expensive drug streptokinase are of minimal benefit when making decisions about individual patients with characteristics different from the trial group).

${ }^{28}$ See, e.g. Alvin 1. Mushlin \& Lou Fintor, Is Screening for Breast Cancer CostEffective?, 69 Cancer 1957 (1992) (emphasizing the need for cost-benefit analyses of breast cancer screening programs); David M. Eddy, Victor Hasselblad, William McGivney \& William Hendee, The Value of Mammography Screening in Women Under Age 50 Years, 259 JAMA 1512 (1988) (detailing the costs and benefits of mammography for women under 50); see also Margaret Tempero, Randall Brand, Karen Holdeman \& Aurelio Matamoros, New Imaging Techniques in Colorectal Cancer, 22 Seminars in Oncology 448 (1995) (reviewing the use of radioimmunodiagnosis, endoscopic and intraoperative ultrasound, magnetic resonance imaging (MRI), and positron emission tomography (PET) in the diagnosis of intra-abdominal malignancies and noting the 
Careful, accurate, and sophisticated outcomes assessment is the best, and indeed, the only reliable way to identify and measure the magnitude of the costs and benefits of many new therapies. Even under the most rigorous and well-controlied circumstances, it is technically very difficult to quantify with any confidence the effects of innovations that represent only marginal improvements over existing techniques or interventions. Necessarily, measurements are subject to various kinds of error and require assumptions that render them little more than best estimates. These observations apply not just to innovative therapies, but also to established treatments, some of which will also be of questionable or marginal value in some or all patients who have received treatment.

But, even with all of its imperfections and difficulties, technology assessment's irreplaceable role in documenting the cost-benefit ratio makes the technique vitally important to the optimal operation of bedside rationing. Technology assessment allows conscientious physicians to think through the possible approaches to diagnosis and treatment in a systematic and informed manner, rather than relying on intuition, anecdote and limited personal experience. Armed with information about medical benefit, efficacy, side effects and overall expense, physicians who have a scientifically sound understanding of the likely costs and effects of treatment choices can formulate more reasoned treatment plans for individual patients in the least harmful and most cost-effective way.

I submit, however, that the key to technology assessment's pivotal role in fostering informed limits on care lies not with the physician, but with the patient. Although sound information is obviously important in permitting physicians to make more informed judgments, it is even more important in enabling a physician to present the basis for his or her judgment in a way that is likely to gain the assent and cooperation of patients. To the extent that the information provided by technology assessment has the power to foster a reduction in the consumption of medical resources, it will do so mainly by creating the conditions under which patients are more likely to go along with reasonable restraints on the provision of care. All too often, the non-specific demand that health care providers "do everything possible" is a manifestation of ignorance and fear rather than reasoned decision-making based on knowledge and concrete information. Without precise data about costs and benefits, patients will be frightened by the inestimable possibility that a chosen path will sacrifice significant palliation or cure. Patients are more likely to accept tradeoffs and risks when their physician's recommendations are backed by the rigorous, trustworthy, and precise scientific estimates of costs and benefits that outcomes assessment data can provide. And not 
only does technology assessment enable physicians to provide patients with convincing and precise evidence of the marginality of the benefits offered by many cutting-edge treatments, but it also allows physicians to pinpoint areas of uncertainty and to advise patients about what is known and unknown concerning the effects of new and existing options. If patients can be made to appreciate the (sometimes flimsy) scientific basis for some interventions, they may go along more readily with recommendations that certain particularly expensive therapies or procedures be forgone or put off.

Some examples show how information technology can foster patientphysician joint decision-making that resolves towards less rather than more interventionist care. Mark Hall illustrates the kind of bottom-up rationing that frequently occurs in practice by offering a hypothetical based loosely on a physician's handling of a knee injury his wife received while playing tennis. ${ }^{29} \mathrm{He}$ states that his wife's physician estimated that there was a ninety percent chance that the injury was a ligament strain (ordinarily treated by resting the affected limb), and a ten percent chance that the injury was a more severe ligament tear, which in turn had a ten percent chance of leading to permanent impairment if left untreated. The most definitive resolution of the diagnostic uncertainty would have been to perform a magnetic resonance imaging scan (costing twelve hundred dollars) immediately. The physician, after consulting with the patient, decided against ordering the scan. A quick recovery proved the gamble harmless.

As Hall points out, this situation does not present the kind of dramatic life-or-death dilemma that dominates the rationing literature. The reality is far less riveting. Through his hypothetical, Hall attempts to provide a more realistic picture of the small, incremental and routine decisions that physicians make every day-decisions like "declining to order a confirming diagnostic test or an extra day in the hospital, prescribing a less expensive drug, or avoiding a referral to a specialist." ". For each of these decisions, the stakes are comparatively small for individual patients, but the costs of indulging extreme risk aversion at every point add up in the aggregate to significantly greater expense for the system.

Hall's example also illustrates that it is a mistake to think of every medical judgment that can be characterized as not doing everything possible as a sharp departure from norms of acceptable medical practice. First, in most routine cases of medical diagnosis and treatment, it is not readily apparent precisely what doing everything possible would mean.

\footnotetext{
Hall, supra note 10 , at $711-12$.
}

* Id at 712 . 
There are often a number of ways to approach a particular medical problem, especially since details of presentation always differ from patient to patient. Flexible conventions, selectively applied through the exercise of individual judgment, are the essence of ordinary medical practice, and can give rise to many alternative strategies for dealing with dayto-day medical scenarios. A measured and gradually escalating sequence of tests and interventions often represents the most acceptable course of action. In creating that sequence-contrary to Professor Elhauge's assumption -the prevailing standard of care is capacious enough to include cases in which "high costs are not justified by minor expected benefits." "31

Although Hall's story is not primarily about the use of cutting edge technologies, it presents a good example of the kind of decision-making at the margin-decision-making that invites "the prudent trimming of incrementally beneficial services" ${ }^{32}$ - that physicians must engage in when determining whether and how to use innovative drugs or treatments. But in order to make decisions at the margins it is necessary to know where the margins are. Hall does not comment on the source or reliability of the probability estimates used in his anecdote. It is easy to devise numbers for use in a hypothetical, but only technology assessment can generate accurate data in a form that can be applied to real-life decisionmaking.

An arena in which sophisticated technology assessment has the potential to play an important role in the evolution of standards of medical practice is in the care of terminally ill and severely afflicted patients, especially among the elderly. Innovations in intensive care have represented genuine medical progress, but have also fomented grass-roots disillusionment with prolonged, expensive and agonizing end-of-life interventions. ${ }^{33}$ This disillusionment has produced a more open public debate on the ethics of setting limits on care, which in turn has fueled shifts in concepts of death with dignity, ${ }^{34}$ a renewed emphasis on home and hos-

${ }^{11}$ Id. at 713 .

ig Id. at 712

"See, e.g., Geoffrey Cowley \& Mary Hager, Terminal Care: Too Painful, Too Prolonged, Newsweek, Dec. 4, 1995, at 74, 75; see also James Studnicki, David V. Schapira, Jon V. Straumfjord, Robert A. Clark, Jan Marshburn \& Dennis C. Werner, A National Profile of the Use of Intensive Care by Medicare Patients with Cancer, 74 Cancer 2366, 2368 (1994) (reporting findings that of 792,584 Medicare beneficiaries admitted with cancer in FY 1990, total Medicare charges were over $\$ 9.3$ billion, of which $\$ 452,229,180$ ( $4.9 \%$ of total) were ICU charges).

"See, e.g., Paul Wilkes, The Next Pro-Lifers, N.Y. Times, July 21, 1996, $\$ 6$ (Magazine), at 22.24 (citing an April 1996 Gallup poll showing that $75 \%$ of Americans believe doctors should be allowed to end the lives of terminally ill patients by painless means at the patient's request); see also Don Colburn, US. Patients' Dying Wishes Often Ignored: Study Finds Hospital Care Depersonalized, Resistant to Change, Wash. Post, Nov. 22, 
pice care for the dying, ${ }^{35}$ and a change in medical conventions regarding the application and withdrawal of care for those nearing the end of life." These changed attitudes can be expected to find expression in greater public and institutional acceptance of physician restraint and selfregulation at the bedside.

Once again, the practical feasibility of physicians and families deciding to forgo heroic treatments depends critically on the availability of reliable information. Patients and doctors need sophisticated and trustworthy data about the patient's prospects for survival and recovery and about the efficacy, side effects and costs of the myriad interventions that are available to the gravely ill. Dr. William Knaus, at the University of Virginia Medical Center, has launched a groundbreaking technology assessment project designed to look at just such parameters. Dr. Knaus's computer program and database, called APACHE, creates profiles of thousands of patients admitted to hospital intensive care units ("ICUs"), carefully records the types of treatments received, and tracks outcomes provided for patients with a spectrum of conditions and characieristics. The program then identifies the specific attributes of patients who benefit from placement in an ICU and from the interventions available in that setting. ${ }^{37}$ Armed with this kind of information, families, physicians, and patients can make more informed decisions about whether and when to opt for intensive care and when to forgo or terminate that option. Because individuals always differ somewhat from the populations profiled

1995, at A1.

${ }^{35}$ See Franklin G. Miller \& Joseph J. Fins, A Proposal to Restructure Hospital Care for Dying Patients, 334 New Eng. J. Med. 1740, 1741 (1996) (advocating restructuring care of hospitalized dying patients by creating a hospice-like unit near the ICU that would emphasize palliation, helping patients and families make decisions about appropriate end of life care); Sidney H. Wanzer et al., The Physician's Responsibility toward Hopelessly IIl Patients: A Second Look, 320 New Eng. J. Med. 845-46 (1989) (advocating home and hospice care as alternatives to intensive hospitalization giving the dying patient the opportunity for privacy, dignity and family closeness).

${ }^{36}$ See, e.g., Daniel Callahan, Medical Futility, Medical Necessity: The Problem-WithoutA-Name, Hastings Ctr. Rpt., July-Aug. 1991, at 30, 34 (asserting "that some will want to extend the notion of [medical] futility well beyond the persistent vegetative state to cases of severe dementia and multi-organ failure"): Wanzer et al, supra note 35, at 847-49 (advocating use of pain relievers even if they shorten life span and examining the practice of assisted suicide and euthanasia as occasionally necessary final steps in a continuum of care for hopelessly ill patients).

${ }^{37}$ See Richard B. Becker et al., The Use of APACHE III to Evaluate ICU Length of Stay, Resource Use, and Mortality after Coronary Artery By-Pass Surgery, $36 \mathrm{~J}$. Cardiovascular Surgery I (1995); William A. Knaus et al., The APACHE III Prognostic System: Risk Prediction of Hospital Mortality for Critically III Hospitalized Adults, 100 Chest 1619 (1991); William A. Knaus et al, An Evaluation of Outcome from Intensive Care in Major Medical Centers, 104 Annals Internal Med. 410 (1986); David T. Wong \& William A. Knaus, Predicting Outcome in Critical Care: The Current Status of the APACHE Prognostic Scoring System, 38 Can. J. Anesthesia 374 (1991). 
in a database, programs like APACHE can never entirely eliminate the risk and uncertainty surrounding care decisions, but they can help to greatly reduce the guesswork inherent in these difficult choices. Once again, patients and families may be more willing to make hard choices when they believe they are operating from sound knowledge rather than engaging in wholly uninformed speculation. Families prefer to face risks that are fairly well known rather than of uncertain magnitude. A physician's ability to lay out the risks in a scientifically credible and precise manner tends to engender greater trust and confidence in the physician's judgment. The value of the type of information generated by a program like APACHE is not confined to cases in which heroic measures can be said to be entirely futile. ${ }^{38}$ Even in cases where patients may receive some minimal benefit-as where interventions may prolong life for days or even weeks - a more reliable projection may enable families and doctors to feel more comfortable forgoing intrusive or expensive treatments or concluding that continuing care carries intolerable costs in lost dignity and prolongation of suffering.

The role proposed here for information technology as an aid to wise limits on care is potentially open to a number of objections. First, as Professor Elhauge points out, information is a public good, and will tend to be in short supply in the private market unless access is restricted. ${ }^{39}$ If

\footnotetext{
${ }^{38}$ Medical ethicists have engaged in a longstanding debate about the scope of the concept of "futile" medical care, and whether accepted medical practice should exclude the requirement of offering futile care. Much of the debate stems from confusion over the definition of futility. The term is sometimes used to refer to care that is usually of no benefit, but may sometimes help in a few cases. Alternatively, it can be applied more narrowly to care that is believed to be of no benefit to anyone. See, e.g., Jeremy Sugarman, Talking About Futility, Hastings Ctr. Rpt., May-June 1996, at 41 (reviewing Lawrence J. Schneiderman \& Nancy S. Jecker, Wrong Medicine (1995)) (discussing various ways in which the term futility is viewed); see also Callahan, supra note 37 , at 31 (discussing the difficulty of defining medical futility and the distinction made between quantitative futility - defined as "an expectation of success that is either predictably or empirically so unlikely that its exact probability is often incalculable" - and qualitative futility - "any treatment that merely preserves permanent unconsciousness or that fails to end total dependence on intensive medical care"') (quoting Lawrence J. Schneiderman, Nancy S. Jecker \& Albert R. Jonsen, Medical Futility: Its Meaning and Ethical Implications, 112 Annals Internal Med. 949, 950, 952 (1990)): Mary A. Crossley, Medical Futility and Disability Discrimination, 81 Iowa L. Rev, 179, 182-202 (1995) (discussing the parameters of the debate over medical futility); Nancy S. Jecker. Medical Futility and Care of Dying Patients, 163 W. J. Med. 287 (1995) (describing a "patient-centered" definition of medical futility in which the measure is whether a given treatment benefits the patient in a way he or she can appreciate, as opposed to merely producing effects on organ systems or body parts). In any event, the futility debate is little more than an abstract exercise unless it is possible to document with some degree of accuracy the effects of interventions commonly applied in end-of-life situations. That is the job of technology assessment.
}

"See Elhauge, supra note 1, at 1574-75. 
outcomes data are to be widely available, the government must get into the business of funding technology assessment projects, which could prove quite expensive if maintained at the level necessary to produce significant effects. Second, this Comment assumes that non-academic practitioners will make regular use of outcomes data in discussing treatment plans with their patients. It may be objected that this represents an unrealistic expectation, because it sets an unreachable standard for busy physicians. Most practicing doctors lack the time and the sophistication to become familiar with the complex details of the outcomes assessment literature. Understanding the significance of the technology assessment data and applying it to particular cases requires careful study and a prolonged investment of effort. For their part, patients cannot function effectively as joint decision-makers unless they have at least a rudimentary appreciation for the scientific method and its application in the clinical setting, and are prepared to accept and assess uncertainty. Most importantly, the paradigm cannot work well unless both doctor and patient are comfortable with the idea that there is more than one reasonable approach to clinical problems, and are prepared to abjure the notion that proper medical care entails a single strategy of doing everything possible at any cost.

There is some basis for believing that the medical profession is currently ill-equipped to make meaningful use of the kinds of information generated by technology assessment. Keeping up with, evaluating and applying the outcomes literature requires providers to devote more time to individual patients than is now generally available. The problem is likely to worsen as medical practice grows increasingly cost conscious and productivity pressures on physicians increase, ${ }^{40}$ Assessing the significance of studies of new technologies also requires an understanding of statistics, epidemiology, and clinical trials design that may not be widespread among practitioners. Nevertheless, the explosion of knowledge and the greater sophistication of routine medical practice have made familiarity with the technology assessment literature, and the willingness and ability to share some of that knowledge with patients, vital components of good patient care. In educating physicians to meet this standard, too little attention has been paid to the development of skills for assessing complex clinical research studies. The medical profession should place greater

\footnotetext{
40 See generally Chatles M. Barker III, Maximizing Efficiency in the Management of the Physician Practice: Survival under Managed Care, J. Health Care Fin., Summer 1996, at 22 (discussing the increased pressure to maximize revenue and control expenses placed on physicians by the growth of managed care); Robert Kuttner, Columbia/HCA and the Resurgence of the For-Profit Hospital Business (First of Two Parts), 335 New Eng. J. Med. 362 (1996) (discussing the medical, ethical and public policy issues raised by the resurgence of for-profit hospitals).
} 
emphasis on physician training in epidemiology, statistics, study design, and technology assessment. ${ }^{41}$ Also, the medical care system should introduce reforms designed to encourage physicians to spend more time talking with patients and thinking about patients' individual needs. ${ }^{42} \mathrm{Al}$ though technology assessment cannot correct the misplaced priorities that create distorted incentives in these areas, these problems must be addressed if the information generated through technology assessment is to form a useful basis for hard choices.

General skepticism about both the desirability and existence of bedside rationing also obstructs the promotion of technology assessment for its potential to encourage restraint in the consumption of medical care. As already noted, both top-down and physician-based rationing have been roundly criticized as a formula for inequity, injustice, and compromise of patient interests. ${ }^{43}$ Payment structures believed to encourage physician-driven reductions in the level of care, including those that offer physicians direct financial incentives to minimize care, have come under fire as creating ethical conflicts of interest. ${ }^{44}$ Also, the physician-based model proposed here does nothing to alleviate the trans-systemic arbitrariness that is the central weakness of "grass-roots" rationing. ${ }^{45}$ There is no doubt that serious inequities can result from decentralized and individualized methods for allocating medical resources in a system where access to insurance, state-of-the-art facilities, and sophisticated, wellinformed care providers varies dramatically. Although the generation of

See generally William L. Roper, William Winkenwerder, Glenn M. Hackbarth \& Henry Krakauer, Effectiveness In Health Care: An Initiative to Evaluate and Improve Medical Practice, 319 New Eng. J. Med. 1197 (1988) (discussing the "effectiveness initiative" and the necessity for physicians to have these skills in order to cope with the complexities of modern practice).

${ }^{42}$ For sources noting this problem, see, e.g., Sherrie H. Kaplan \& Lisa M. Sullivan, Maximizing the Quality of the Physician-Patient Encounter, $11 \mathrm{~J}$. Gen. Internal Med. 187, 187-88 (1996) (arguing that the decreased duration and frequency of patient office visits for cost-containment purposes should be countered, in part, with increased training of physicians to maximize interpersonal contact with patients); A. James Lee \& Janet B. Mitchell, Physician Reaction to Price Changes: An Episode-of-Care Analysis, Health Care Financing Rev., Winter 1994, at 65 (describing the 1989 Medicare fee schedule reform as redressing the previous system's "overpay[ment]" of technical procedures and "underpay[ment]" of office visits).

${ }^{43}$ See supra notes 3-6 and accompanying text.

4 See Orentlicher, supra note 11, at 162-63 (reviewing legislation and proposals to restrict the use of payments to physicians, which are designed to induce them to reduce or limit medically necessary services); see also Woolhandler \& Himmelstein, supra note 18 , at 1706 (questioning the effectiveness of financial incentives in inducing physicians to limit care); cf. Robert Pear, U.S. Shelves Plan to Limit Rewards to H.M.O. Doctors, N.Y. Times, July 8, 1996, at A1 (reporting on the Department of Health and Human Service's decision to suspend the enforcement of rules restricting HMOs' ability to use financial incentives to reward doctors for controlling the use and cost of medical care).

${ }^{2}$ See Hall, supra note 10, at 714-19; Orenticher, supra note 11, at 165. 
information through technology assessment presents the potential for eventual consensus on the proper use of new technologies by offering a common factual foundation for decision-making, it does little in itself to enforce comprehensive consistency in the use of medical resources, and may introduce new inequities through the misallocation of a key resource-information about the effects of treatment options-in favor of the well-informed and well-heeled. Although this Comment does not deal with the merits of these issues, it recognizes that accepting the role for technology assessment outlined here depends on endorsing a normative view of rationing as a not entirely undesirable feature of the medical care system, and on believing that the dangers posed by a system that routinely tolerates the sacrifice of potentially beneficial care can be minimized and controlled.

Accepting the thesis of this Comment also depends on accepting the prediction that, all else being equal, the provision of outcomes information will influence actual decision-making. Will making the physicianpatient interaction better informed actually lead to a reduction in the consumption of medical care? That question must ultimately be answered empirically. At this symposium, Professor Trebilcock suggested that a reduction in care will never materialize because rationing is a straightforward function of the economic pressures placed on the individual doctor and patient; in the absence of direct financial incentives to conserve resources, collective action problems and self-interest will effectively prevent rationing from occurring. ${ }^{\text {th }}$ That view is almost certainly too simplistic, because it discounts the possibility that conventions and norms influence medical practice, and that norms not only can persist without economic incentives in their favor but can even survive in the face of mild economic penalties. It also fails to take account of forces currently at work in some parts of the health care system that would tend to maintain pre-existing norms of medical practice that were shaped by the need to deal with scarcity. ${ }^{47}$ Those forces can have influence even outside the strongholds of cost-conscious medical practice (such as managed care plans and HMOs) that reinforce them, and will tend to act as a counterweight to the absolutist norms and need-driven reimbursement systems (such as fee-for-service) that oppose any limits on care. The prevalence and existing modes of bedside rationing are thus unlikely to be a straightforward function of the direct economic incentives on individual actors. Rather, they will be a complex product of a host of factors, which include (but are not limited to) the range and intensity of present

\footnotetext{
1996.

Remarks of Michael Trebilcock at Olin/Virginia Law Review Symposium, Mar. 1 ,

SSee supra notes $14-17$ and accompanying text.
} 
cost pressures on physicians and patients system-wide.

So far, this Comment has focused on the role of technology assessment in enabling physicians to present options to patients more intelligently and effectively. Technology assessment can also work to undermine the absolutist paradigm by providing the basis for cost-shifting structures that exert direct pressure on patients to reduce the consumption of medical care. Familiar devices, such as copayments and deductibles, already provide patients with some modest financial incentives to forgo or delay care in general, but do little to differentiate among different types of care. Technology assessment offers the possibility of applying cost-shifting devices in more targeted ways. Better information would enable insurers to construct a graduated cost-shifting scheme in which reimbursement is tied to the value of available interventions. Such a calibrated system could attempt to discourage patients from consuming care with a higher cost-benefit ratio by shifting a greater portion of the costs of marginally effective or extraordinarily expensive new treatments to consumers.

It would be impossible in practice to create a comprehensive schedule of tinancial incentives that precisely reflects the marginal costs and benefits of the full range of care. Even if the methodological problems assessing the costs and benefits of interventions could be solved, ${ }^{48}$ there are simply too many permutations to make that project feasible. ${ }^{49}$ A more limited and achievable goal would be to attempt to discourage the overuse of marginally effective services by establishing a purely forwardlooking system of graduated copayments or surcharges covering only new technologies or recently approved therapies, which tied the magnitude of coverage of costs for new services to their expected effects. As previously noted, a significant number of new drugs and treatments are costly but of low or questionable utility. ${ }^{50}$ As new technologies come along, an insurer or provider could evaluate the costs and review what is known about the expected magnitude and probability of benefits. The new treatment could be compared to previously available or less expensive alternatives. Based on these parameters, the insurer could then agree to cover some portion of the costs, with the rest being charged directly to the patient. The greater the benefit expected from the new intervention, the more complete the coverage, and the less the patient must pay di-

\footnotetext{
* See supra notes 13-17 and accompanying text.

${ }^{4}$ See Orentlicher, supra note 11 , at 189 ("To rely exclusively, or even primarily, on patient-based incentives [to ration care] would require a degree of contract specificity that is not achievable in health care, For patients to agree to less care in return for lower costs, they would have to be told exactly what kinds of care and how much care they would receive at each premium level.")

si See supra notes $20-25$ and accompanying text.
} 
rectly. The result would be a schedule of cost-sharing that is tied closely to contemporaneous knowledge for experimental treatments like bone marrow transplantation, or new drugs like IPA for heart attacks or Tacrine for Alzheimer's disease." Creating a system like the one proposed would depend critically on detailed information gathered through technology assessment.

To be sure, this proposal shares drawbacks with any approach that offers patients direct financial incentives to avoid care. It is difficult to work out the terms by which cost-sharing can be combined with providing care to the poor. Any shift of costs directiy to patients makes the distribution of care more sensitive to ability to pay. Many new technologies will effectively be placed off-limits for the indigent or uninsured unless the government pays the full freight, which raises troublesome issues of horizontal equity by forcing decisions about what kinds of expensive care will be allocated directly to the poor. There are also enormous practical difficulties in formulating and implementing a service-by-service schedule of shared payments, even on a limited or prospective basis. Creating a graduated system would require establishing a workable and acceptable measure of medical benefit. ${ }^{2}$ Even if such a measure could be devised in principle, decisions in actual cases would require applying generalized findings gleaned from group studies to unique individuals - a process that doctors and patients might find intrusive or inept, especially when money is so directly at stake.

On the other hand, efforts to tie a patient's share of payments for a new technology to projected benefits might prove more palatable to absolutist watchdogs than other proposals for limiting care. For one thing, a shared payment paradigm might help bring about an important change

\footnotetext{
${ }^{51}$ For a discussion of these experimental treatments, see supra note 27 and accompanying text.

${ }^{52}$ Profesor Elhauge has addressed the difficulties of trying to assign fungible "value" to medical benefit from many different kinds of treatments. See Elhauge, supra note 1 at 1589-92; Elhauge, Allocating Health Care Morally, supra note 8, at 1493-1526; see also Jan Paul Acton, Measuring the Monetary Value of Lifesaving Programs, Law \& Contemp. Probs., Autumn 1976, at 46, 46-49 (arguing the need for an objective and readily applicable measure of benefit from medical procedures to facilitate a cost-benefit comparison between health and safety programs and other government programs); Maria A. Friedman, Issues in Measuring and Improving Health Care Quality, Health Care Financing Rev., Summer 1995, at 1,4-9 (describing the difficulty in measuring quality and the need for a workable, uniform definition); Richard Zeckhauser \& Donald Shepard, Where Now For Saving Lives?, Law \& Contemp. Probs., Autumn 1976, at 5, 11-15 (employing use of "Quality Adjusted life Years" to determine efficient health resource alfocation); Caitlin J. Halligan, Note, "Just What The Doctor Ordered": Oregon's Medicaid Rationing Process and Public Participation In Risk Regulation, 83 Geo. L.J. 2697. 2712-13 (1995) (describing negative reaction to Oregon's use of a public survey to lank medical procedures for the purpose of creating a priority list of reimbursable treatment as part of Oregon's Medicaid Rationing Process).
} 
in thinking about the allocation of medical care. Current coverage arrangements foster an all-or-nothing approach to the use of medical technologies. Although an insurer's denial of payment or coverage is not the same as a rule barring a patient from obtaining care (since a patient can always choose to pay out-of-pocket for what is not covered), the two situations have converged in the minds of many participants in the health care system, adding fuel to the fire of absolutism. ${ }^{33}$ That convergence is not surprising, in light of insurers' habit of sharply classifying all medical intervention into two categories: The medically necessary (which sweeps in treatments thought to offer any benefit whatsoever, however slight) and the unnecessary or futile (which is equated with no benefit). ${ }^{54}$ Once standard deductibles or copayments have been satisfied, ${ }^{35}$ care deemed "necessary" is customarily paid for at a fixed rate. That rate is insensitive to how effective a treatment is, or whether there are less expensive or virtually equivalent alternatives. Treatments deemed "unnecessary" are excluded from coverage altogether. It is this bipolar approach that fosters the equation of coverage to care, and arouses resistance to an insurer's refusal to pay even for the most expensive and marginally useful interventions on the ground that "medically necessary" care has been "denied." Departing from a strictly categorical scheme that classifies all treatments as either "necessary" or "unnecessary" might help to lessen the resistance of consumers who are asked to pay more. Different medi-

\footnotetext{
${ }^{53}$ See Elhauge, Allocating Heaith Care Morally, supra note 8, at 1493-1526 (suggesting that refusal to pay is tantamount to an absolute prohibition on care).

isee, e.g., 42 U.S.C. \$1395y(a)(1)(A) (1994) (services not part of "reasonable and necessary" care excluded from Medicare coverage). In 1989, the Health Care Financing Administration ("HCFA") defined a "necessary" service as one that "is safe, effective, non-investigational, and appropriate," and defined "appropriate" as meaning that the service "is furnished in a setting commensurate with the patient's medical needs and condition, and furnished by qualified personnel." Criteria and Procedures tor Making Medical Services Coverage Decisions That Relate to Health Care Technologies, 54 Fed. Reg. 4302, 4307, 4308 (1989) (proposed rule) (cited in Maxwell J. Mehlman, Jeffrey R. Botkin, Alan Scarrow, Amy Woodhall, Julie Kass \& Ellen Siebenschuh, Coverage of Genetic Technologies under National Health Reform, 55 Am. I. Hum. Genetics 1054, 1055,1060 (1994)); see also Callahan, supra note 36 , at 33 (criticizing previous attempts to define medically necessary care as opening the door to an unlimited range of benefits regardless of costs and failing to take into consideration the efficacy of available treatment); Note, supra note 52, at 2706-16 (describing the Oregon Medicaid Rationing Process Commission's insistence on a fixed minimal standard of essential services).

* For example, Medicare beneficiaries are charged a fixed monthly premium for insurance under Medicare Part B (which covers outpatient charges and services). The program also pays for a fixed percentage $(80 \%)$ of charges incurred under this Part. Under Part A, which covers in-hospital services, there is a deductible of about $\$ 600$, which the patient pays out of pocket. The program pays a fixed amount per day for charges over and above that amount. See U.S. Dep't of Health \& Human Services. The Complete Medicare Handbook 18-19, 34-35 (Eugene Landay ed., 1990) (reviewing Medicare deductibles and reimbursement schedules).
} 
cal strategies present a range of benefits and drawbacks, and are attended by a spectrum of uncertain effects. It is truer to medical realityand may well prove more acceptable to absolutists-to adopt an approach that attempts to reflect the ongoing, dynamic state of knowledge about the value of care.

Although the development of a truly complete understanding of the costs and benefits of medical care options is an ideal that may well be out of reach for both practical and theoretical reasons, our current level of knowledge falls far short of the limits that may eventually be encountered. Technology assessment and outcomes research are in their infancy, and their potential value in clarifying the most basic parameters of cost and benefit for new and existing interventions has only begun to be explored. We have a long way to go before diminishing returns set in, and are still at a stage in which serious efforts to chip away at large areas of ignorance could aid in the making of resource-saving choices. By showing that some risks are not as great as feared, nor some benefits as great as hoped for, technology assessment can help patients, families, and providers face up to hard decisions in planning care. These results cannot be realized unless the medical community commits itself to technology assessment that generates a broad range of reliable and useful information. 